Article

\title{
The Potential of Functionalized Ceramic Particles in Coatings for Improved Scratch Resistance
}

\author{
Caterina Lesaint Rusu ${ }^{1}$, Malin Brodin ${ }^{2}$, Tor Inge Hausvik ${ }^{3}$, Leif Kåre Hindersland ${ }^{3}$, \\ Gary Chinga-Carrasco ${ }^{2}$ (D), Mari-Ann Einarsrud ${ }^{1}$ (i) and Hilde Lea Lein ${ }^{1, *}$ \\ 1 Department of Materials Science and Engineering, NTNU, N-7491 Trondheim, Norway; \\ caterina.l.rusu@ntnu.no (C.L.R.); mari-ann.einarsrud@ntnu.no (M.-A.E.) \\ 2 RISE PFI AS, 7034 Trondheim, Norway; malin.brodin@rise-pfi.no (M.B.); \\ gary.chinga.carrasco@rise-pfi.no (G.C.-C.) \\ 3 Berry Alloc, 4580 Lyngdal, Norway; TorInge.Hausvik@berryalloc.com (T.I.H.); \\ LeifKare.Hindersland@berryalloc.com (L.K.H.) \\ * Correspondence: hilde.lea.lein@ntnu.no; Tel.: +47-73-55-08-80
}

Received: 28 May 2018; Accepted: 16 June 2018; Published: 19 June 2018

\begin{abstract}
The top layer of a typical high pressure floor laminate (HPL) consists of a melamine formaldehyde (MF) impregnated special wear layer (overlay) with alumina particles. This top layer plays a crucial role in determining the mechanical properties of the laminate. For HPLs, scratch resistance and scratch visibility are particularly important properties. This study aimed to improve the mechanical properties, particularly the scratch resistance, by adjusting the composition of the overlay. Laminates containing alumina particles were prepared and tested. These alumina particles were additionally functionalized with a silane coupling agent to ensure better adhesion between the particles and the resin. The functionalized particles led to enhanced scratch resistance of the laminates as well as improved dispersion of the particles within the resin. Micro scratch testing revealed that by using functionalized particles, the scratch surface damage was reduced and the recovery characteristics of the surface layer were improved. Higher scratch resistance and scratch hardness were thus obtained, along with a reduced scratch visibility.
\end{abstract}

Keywords: high pressure laminates (HPL); overlay; alumina; functionalization; silane coupling agent; scratch resistance; scratch visibility; scratch hardness

\section{Introduction}

Decorative laminates are widely used products with many applications within both home interior design and commercial settings. High pressure laminates are the most commonly used laminates consisting of multiple layers of kraft papers impregnated with phenol formaldehyde (PF) resin, laminated together with decorative paper impregnated with melamine formaldehyde (MF) [1]. For decorative laminates, the top surface has a double role: providing the final product with an excellent appearance and protecting the substrate from external damage [2]. Even a few scratches, though most of them are a few micrometers in depth, can deteriorate the original appearance [3] and in some cases, may even affect functionality by rendering them more vulnerable to other types of strain (flexion, impact, fatigue, etc.) [4]. Hence, scratch resistance and scratch visibility are very important factors for the top functional coatings in laminate floors. The melamine impregnated high-quality overlay paper based on $\alpha$-cellulose [5] used on top of the decorative layer contains alumina particles to provide high scratch and abrasion resistance [1] to the finished product.

For coating applications such as laminate flooring where the appearance is particularly important, scratch visibility is a very significant issue [6]. Scratch visibility is essentially caused by the scattering 
of incident light due to high roughness or an uneven surface structure prompted by scratching (e.g., cracks, crazes, etc.) [7]. When these flaws on the damaged surface are larger than the wavelength of visible light, the scratches become visible [7]. The scratch visibility is known to correlate well with parameters like scratch hardness, scratch depth, surface roughness on the scratch path [6], coefficient of friction of the surface, and filler-matrix interface strength as well as the elastic recovery characteristics of the polymer [4]. The damage caused by plastic flow generally has a lower impact on the scratch visibility than brittle damage due to less scattered light $[8,9]$.

In general, the addition of ceramic particles into a polymeric matrix is beneficial for scratch resistance $[10,11]$ and depends on the type, morphology, and size of the particles [12-16], but also on their amount, hardness, and dispersion state [17]. Alumina has successfully been used as reinforcement for organic coatings with improved scratch resistance in a number of previous studies, for example, when added to Nylon-11 [15], melamine films [18] or PTFE [19]. A further improvement in the scratch resistance can be obtained through the strengthening of the polymer/particle interface [4], which will improve the dispersion state of the particles within the polymer matrix [20] and reduce the stresses associated with polymerization shrinkage [21] among others. Silane coupling agents are commonly used for functionalization, along with amines, carboxilates, phosphonates, etc., [22] as they can act as chemical bridges between the particle and the polymer. The silane can be covalently bound to the particle's surface through the silicon atom, and the alkyl chain will bond to the polymer. Important improvements in scratch resistance while maintaining good transparency have been achieved in the presence of ceramic nanoparticles such as silica [20], titania [23], and alumina [24] functionalized with silane coupling agents. Silica nanoparticles functionalized with three different trialkoxysilane agents and incorporated in polyacrylate yielded nanocomposite films with higher scratch and wear resistance as well as improved viscoelastic properties [20]. Titania nanoparticles functionalized with 3-aminopropyltrimethoxysilane (APTMS) greatly improved the resistance to abrasive wear and the particle dispersion within a Polyamide 11 matrix [23]. Better scratch resistance along with a good dispersion of the particles has also been obtained when incorporating alumina nanoparticles functionalized with [2-(3,4-epoxycyclohexyl)ethyl]trimethoxysilane in a polyurethane coating [24]. A significant improvement of the critical load, a uniform dispersion of the particles in the polymer as well as low residual scratch depths when compared to the neat polymer were obtained for all functionalized alumina containing samples even at relatively low particle loadings (6 vol.\%) [24]. As such, a general trend in enhanced mechanical properties like wear resistance and resistance to scratch has been observed when incorporating functionalized nanoparticles into a polymer matrix.

For micron scale ceramic particles, the influence of functionalization on the properties of polymer composites has yet to be extensively studied. Additionally, there is a need for further work on the use of functionalized ceramic particles in laminate flooring in general and functionalized alumina particles in particular. The aim of this work was therefore to improve the mechanical properties of floor laminates, and especially the resistance to scratch through the addition of functionalized ceramic particles. Alumina particles were chosen as these particles are included in the overlay of commercial laminates. Today's laminates contain rather large alumina particles $(\sim 100 \mu \mathrm{m})$; however, these are hard to functionalize due to the size and the low surface area, and smaller particles are therefore preferred. Sub-micron particles are chosen over nano sized particles due to their advantages in terms of cost and availability. A silane coupling agent was selected for the functionalization of the alumina particles based on its compatibility with both the alumina particles and the MF polymer matrix. An improvement in the dispersion of the alumina particles as well as in the scratch resistance of the laminates were obtained through the addition of functionalized alumina particles, and the influence of the functionalization of alumina particles on the scratch resistance of laminates is discussed by evaluating different aspects such as residual scratch depth and width, scratch hardness, scratch visibility, and scratch deformation mode. 


\section{Materials and Methods}

\subsection{Materials}

A commercial grade of MF resin (Dynea, Lillestrøm, Norway) in the form of a pre-condensate solution with a viscosity of $24 \mathrm{mPa} \cdot \mathrm{s}$ at $25^{\circ} \mathrm{C}$, a dry content of $50 \mathrm{wt} \%$, and pH 9.5 was used for the impregnation of the overlay paper. Overlay paper, decorative paper impregnated with MF and kraft papers impregnated with PF resin (supplied by Nordic Paper, Greåker, Norway) were used for manufacturing the laminates. A slip agent (formula and manufacturer unknown), wetting agent (Poly(oxy-1,2-ethanediyl),alfa-(2-propylheptyl)-omega-hydroxyl-, INEOS Melamines $\mathrm{GmbH}$, Frankfurt am Main, Germany), and curing agent (formula and manufacturer unknown) were used as additives for the preparation of the overlay impregnation solution.

Alumina particles ( $\alpha$-aluminum oxide, $\mathrm{Al}_{2} \mathrm{O}_{3}$, purity $99.99 \%$ ) with an average size ranging between 0.5 and $1 \mu \mathrm{m}$ (Inframat Advanced Materials, Manchester, CT, USA) were used as reinforcement for the MF resin. The average size was provided by the manufacturer. The specific surface area of the alumina powder was measured by nitrogen adsorption analysis to be $6.3 \pm 0.12 \mathrm{~m}^{2} / \mathrm{g}$. The morphology of the particles obtained through SEM is shown in Figure 1a. The particles were irregularly shaped and their sizes corresponded to the range reported by the supplier.

$(\gamma)$-Glycidoxypropyl-trimethoxy silane (>98.0\%), also referred to as AP-Silane 51, (Advanced Polymer, Inc., Carlstadt, NJ, USA) was used for surface functionalization of the alumina particles. The compound was selected based on its compatibility with both the alumina and the MF resin. The chemical structure of the compound is shown in Figure 1b. Tetrahydrofuran (THF, anhydrous, containing 250 ppm butylated hydroxytoluene (BHT), purity $\geq 99.9 \%$, Advanced Polymer, Inc., Carlstadt, NJ, USA) was used as the solvent for the functionalization of the particles. BHT (200-300 ppm) was added to THF by the manufacturer to prevent the formation of explosive organic peroxides during storage [25].

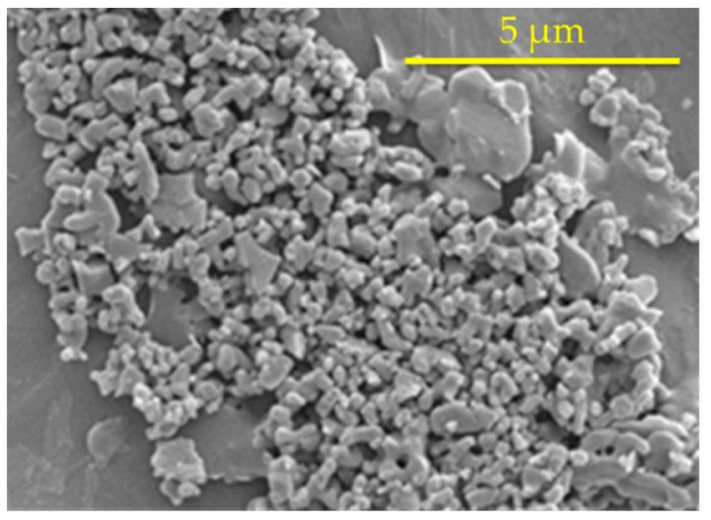

(a)

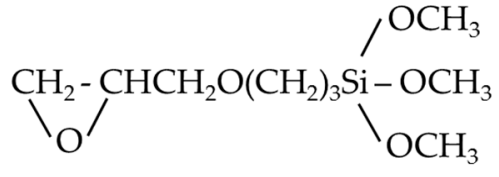

(b)

Figure 1. (a) SEM image of the alumina particles; (b) Chemical structure of the silane coupling agent used in this work, $(\gamma)$-Glycidoxypropyl-trimethoxy silane [26].

\subsection{Methods}

Surface functionalization of the alumina particles was carried out using the following procedure reported elsewhere [27] with slight modifications: alumina particles ( $8 \mathrm{~g})$ were added to THF (25 mL) and the mixture was ultrasonically stirred for $15 \mathrm{~min}$ using a Bandelin Sonorex RK 255 Transistor bath operating at $35 \mathrm{~Hz}$ (Bandelin, Berlin, Germany). The dispersion was then added to the treatment solution containing the silane agent $(4 \mathrm{~g})$ dissolved in THF $(25 \mathrm{~mL})$, after which the resulting colloidal dispersion was stirred ultrasonically for $1 \mathrm{~h}$ at room temperature and subsequently separated by sedimentation. Finally, the sedimented particles were rinsed three times with THF to remove the organic residuals, then dried in a vacuum oven at room temperature [27]. Thermogravimetric analysis 
(TGA) was performed on the as-received and functionalized alumina particles using a Netzsch thermal analysis system 4 (STA449, Erich NETZSCH GmbH \& Co. Holding KG, Selb, Germany). The temperature range was $30-700{ }^{\circ} \mathrm{C}$ with a heating rate of $10^{\circ} \mathrm{C} / \mathrm{min}$. Samples of approximately $30 \mathrm{mg}$ were weighed and added to the alumina crucibles. Synthetic air was used as the flow medium with a flow rate of $25 \mathrm{~mL} / \mathrm{min}$.

Five types of laminates were manufactured by assembling a MF impregnated overlay paper containing alumina particles with a MF pre-impregnated decorative paper and two PF pre-impregnated kraft papers. The impregnation of the overlay paper was performed manually using a No. 9 Tan meter bar (RK Print Coat Instruments, Hertfordshire, UK). The impregnation resin was prepared by adding a curing agent $(0.6 \mathrm{wt} \%)$, wetting agent $(0.1 \mathrm{wt} \%)$, and slip agent $(0.1 \mathrm{wt} \%)$ to a MF pre-condensate. Alumina particles (functionalized or non-functionalized) were added in two different concentrations: 5 and $10 \mathrm{wt} \%$. A reference laminate without particles was prepared for comparison. After impregnation, the coatings were allowed to dry at room temperature for three to four days before being pressed for $1 \mathrm{~h}$ at $115^{\circ} \mathrm{C}$ and $7.35 \mathrm{MPa}$ using a Fontijne press LPB 300 apparatus (Fontijne Presses, Barendrecht, The Netherlands).

The cross-sections of selected laminates were investigated by SEM using a Hitachi SU 3500 (Hitachi High-Technologies Corporation, Minatoku, Tokyo, Japan) apparatus. Sections of approximately $2-3 \mathrm{~cm}^{2}$ from each sample were embedded in epoxy resin under vacuum. The prepared blocks were dried at $45^{\circ} \mathrm{C}$ to cure the epoxy, then ground with $\mathrm{SiC}$ paper and polished with diamond particles with 9 and $1 \mu \mathrm{m}$ sizes. The samples were coated with carbon prior to SEM investigation. The images were acquired in backscatter electron imaging mode (BEI) with an accelerating voltage of $5.00 \mathrm{kV}$. The surface morphology of the scratched laminates was also investigated by SEM. For this, small sections of approximately $1 \mathrm{~cm}^{2}$ were cut and sputter coated with a thin layer of gold. The images were acquired in secondary electron mode (SE) with an accelerating voltage of $5.00 \mathrm{kV}$.

The scratch resistance of the laminates was tested using an Anton Paar Tritec Micro-Combi Tester (Anton Paar GmbH , Graz, Austria) equipped with a Rockwell C-type diamond indenter, with a spherical tip and a radius of $100 \mu \mathrm{m}$. Two types of scratch tests were carried out where the load was applied either at constant mode $(6 \mathrm{~N})$ or at progressive mode $(0-10 \mathrm{~N})$. A constant scratch rate of $1 \mathrm{~mm} / \mathrm{min}$ was applied for the constant load measurements and $1.66 \mathrm{~mm} / \mathrm{min}$ for the progressive load measurements. The scratch profile length was 5-6 mm. At least three scratches were performed on two different replicates of each sample and the penetration depth $\left(P_{\mathrm{d}}\right)$ and the residual scratch depth $\left(R_{\mathrm{d}}\right)$ were recorded. The optical critical load, scratch width, and morphology were determined by means of optical microscopy and SEM. The elastic recovery $f(\%)$ was obtained using Equation (1) [2]:

$$
f=\left[\left(P_{\mathrm{d}}-R_{\mathrm{d}}\right) \cdot 100\right] / P_{\mathrm{d}}
$$

Scratch resistance in terms of the residual scratch deformation of the scratch width was also taken into consideration. The scratch width was calculated as the average of the width data measured from the SEM images of the scratch tracks. The scratch hardness, defined as the normal load of the indenter over the load bearing area, was calculated using Equation (2) [28]:

$$
\mathrm{H}_{\mathrm{s}}=4 q P / \pi w^{2}
$$

where $w$ is the post-scratch width in millimeters; $P$ is the normal load in Newtons; and $q$ is a dimensionless parameter $(1<q<2)$ that depends on the extent of elastic recovery of the polymer during scratching. Most commonly, for polymeric materials, the value of $q$ is considered to be 1 [29]. For this study, the value of $q$ was considered to be 1 .

The optical critical load, $L_{\mathrm{c}}$, defined as the normal load at which the first damage fulfilling contrast, size, and continuity criteria at the same time occurs [30], was determined. The resistance to scratch was also determined using a Taber Scratch tester model $551(230 \mathrm{~V}, 50 \mathrm{~Hz})$ in accordance with NS-EN 438-2 [31]. During this test, laminates were cut into 10-cm diameter discs and secured 
on the instrument turntable, then successively increasing loads (starting with $1 \mathrm{~N}$ ) were applied and the scratches were examined visually. The scratch resistance was determined as the minimum load necessary to produce a continuous scratch mark visible to the naked eye from different angles.

\section{Results}

\subsection{Thermogravimetric Analysis of Functionalized Alumina}

TGA of the as-received alumina particles and the functionalized alumina particles is shown in Figure 2. The change in mass indicates the mass loss of the particles as the temperature increased. The functionalized particles showed a significant two-step mass loss when compared to the as-received particles, proving the existence of the silane coupling agent, which decomposes at higher temperatures. The mass loss between 50 and $140{ }^{\circ} \mathrm{C}$ corresponding to the evaporation of adsorbed moisture and water resulted from the condensation between adjacent silane agents and was not taken into account when calculating the mass loss. The mass loss between 230 and $450{ }^{\circ} \mathrm{C}$ corresponded to the covalently bound coupling agent. The mass loss was $\sim 1.7 \mathrm{wt} \%$ (measured from the plateau at $\sim 150{ }^{\circ} \mathrm{C}$ ).

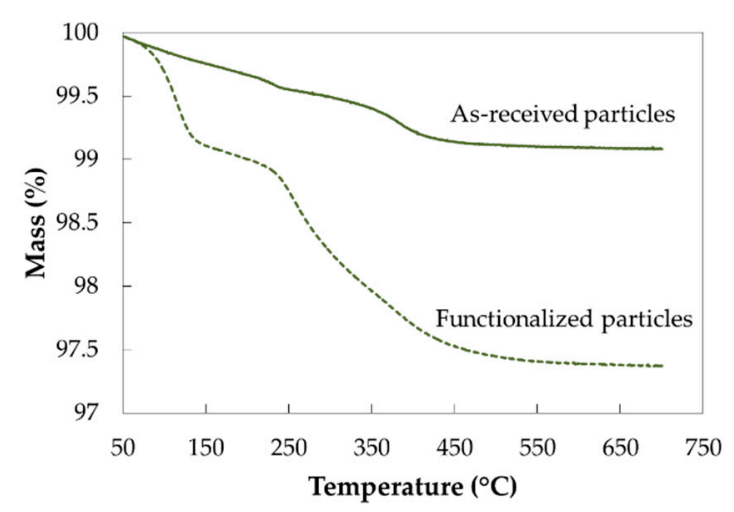

Figure 2. Mass (\%) as a function of temperature of the as-received (solid line) and the functionalized (dotted line) alumina particles.

\subsection{Cross-Sectional Analysis of the Laminates}

The effect of the surface modification on the dispersion of the alumina particles within the resin was observed through SEM of the cross-section of the laminates, and the images are shown in Figure 3.

The alumina particles were homogeneously distributed after functionalization when compared to the as-received particles.

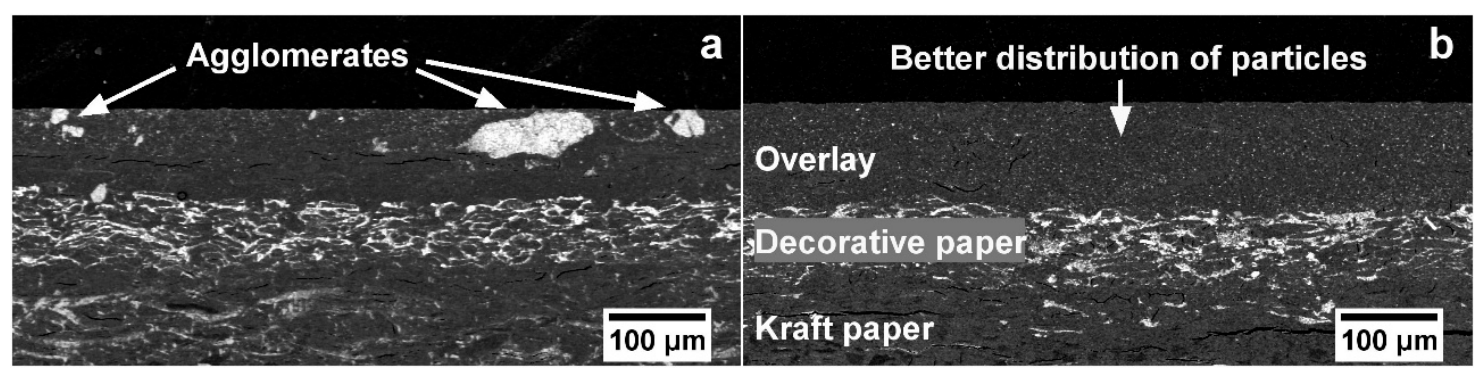

Figure 3. Cross-sectional SEM images of laminates with (a) $10 \mathrm{wt} \%$ of as-received alumina particles and (b) $10 \mathrm{wt} \%$ of functionalized alumina particles.

\subsection{Scratch Resistance Measured in Accordance with Standard NS-EN 438-2}

The scratch resistance was improved using the surface functionalized alumina particles. The scratch resistance results obtained through a visual inspection of the laminates after the scratch 
test performed in accordance with the NS-EN 438-2 standard are presented in Table 1. Using the SEM images of the scratch tracks produced through micro scratch testing, the scratch width was calculated as the average of the width data measured from the images. The values are also reported in Table 1.

The best performance was observed for the laminates containing 5 and $10 \mathrm{wt} \%$ of functionalized particles which were ranked with $5 / 6$ and 6 , respectively. The sample with the higher content of functionalized alumina particles showed better scratch resistance. For the laminates containing as-received particles, the opposite trend was observed, as the sample containing the higher amount of particles $(10 \mathrm{wt} \%)$ proved to be less scratch resistant than the one containing $5 \mathrm{wt} \%$. This could be due to the formation of agglomerates in the laminate with a greater amount of non-functionalized particles.

Table 1. Scratch resistance (according to standard NS-EN 438-2) and scratch widths (from micro scratch testing) of laminates containing as-received and functionalized alumina particles.

\begin{tabular}{cccc}
\hline Alumina Particle Concentration (wt \%) & Functionalization & Scratch Resistance (N) & Scratch Width $(\boldsymbol{\mu m})$ \\
\hline 0 & - & 4 & $131 \pm 5$ \\
5 & No & 5 & $118 \pm 3$ \\
10 & No & 4 & $123 \pm 6$ \\
5 & Yes & $5 / 6$ & $120 \pm 5$ \\
10 & Yes & 6 & $108 \pm 7$ \\
\hline
\end{tabular}

\subsection{Scratch Resistance Measured through Micro Scratch Testing}

Figure 4 shows the extended scratch test results of the laminates using a micro scratch tester. Figure 4a shows the residual depth curves after a constant load of $6 \mathrm{~N}$ as a function of the length of the scratch and Figure $4 \mathrm{~b}$ shows the residual scratch depth after progressive load testing from 1 to $10 \mathrm{~N}$ as a function of the scratch length.
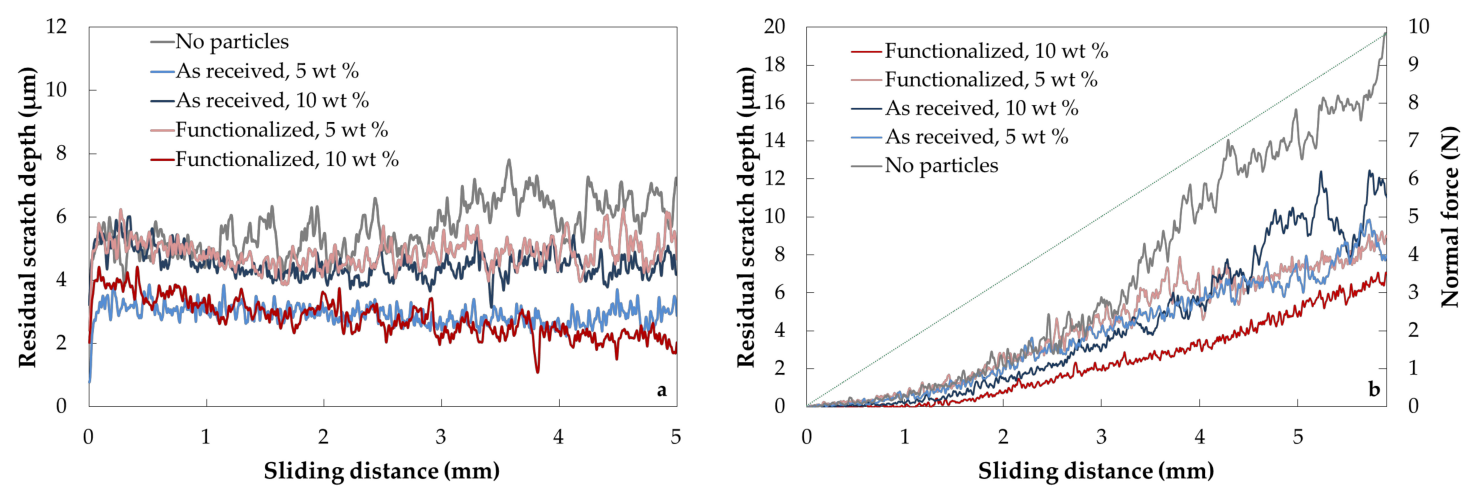

Figure 4. Residual depth after the scratch test of the laminates: (a) with a constant load of $6 \mathrm{~N}$ as a function of scratch length, and (b) with progressive load from 0 to $10 \mathrm{~N}$ as a function of scratch length.

From Figure 4a, the best performing laminate was the one containing $10 \mathrm{wt} \%$ of functionalized alumina particles, showing the lowest scratch depth. Compared to the laminate with $10 \mathrm{wt} \%$ of as-received particles, the scratch depth was more than halved from the original value (from an average $5 \mu \mathrm{m}$ for the last two $\mathrm{mm}$ for the non-functionalized to $2.1 \mu \mathrm{m}$ for the functionalized). Differences were also observed for the $5 \mathrm{wt} \%$ of load, however, the laminate with the as-received particles performed better, which shows that the amount of incorporated alumina particles is important. The worst performing laminate was the one containing no particles, confirming that the presence of ceramic particles is crucial.

Figure $4 \mathrm{~b}$ shows the residual scratch depth curves after progressive load testing and confirmed that laminates with functionalized particles had the best performance. The laminates with $10 \mathrm{wt} \%$ of functionalized alumina were significantly better and this was especially visible for loads above $5 \mathrm{~N}$. For the $5 \mathrm{wt} \%$ of solid loading, there was no significant difference. On the other hand, the laminate 
without particles showed the far largest depths, with a more jagged depth profile as a function of normal load, reflecting a higher roughness of the scratch track for this sample due to brittle fracture within the scratch track.

\subsection{Scratch Microstructure and Scratch Behavior}

The measured scratch resistance must be seen in conjunction with the changes in microstructure and scratch behavior. Figure 5 shows the SEM images of the residual scratch patterns of the laminates after micro scratch tests with a $6 \mathrm{~N}$ load.
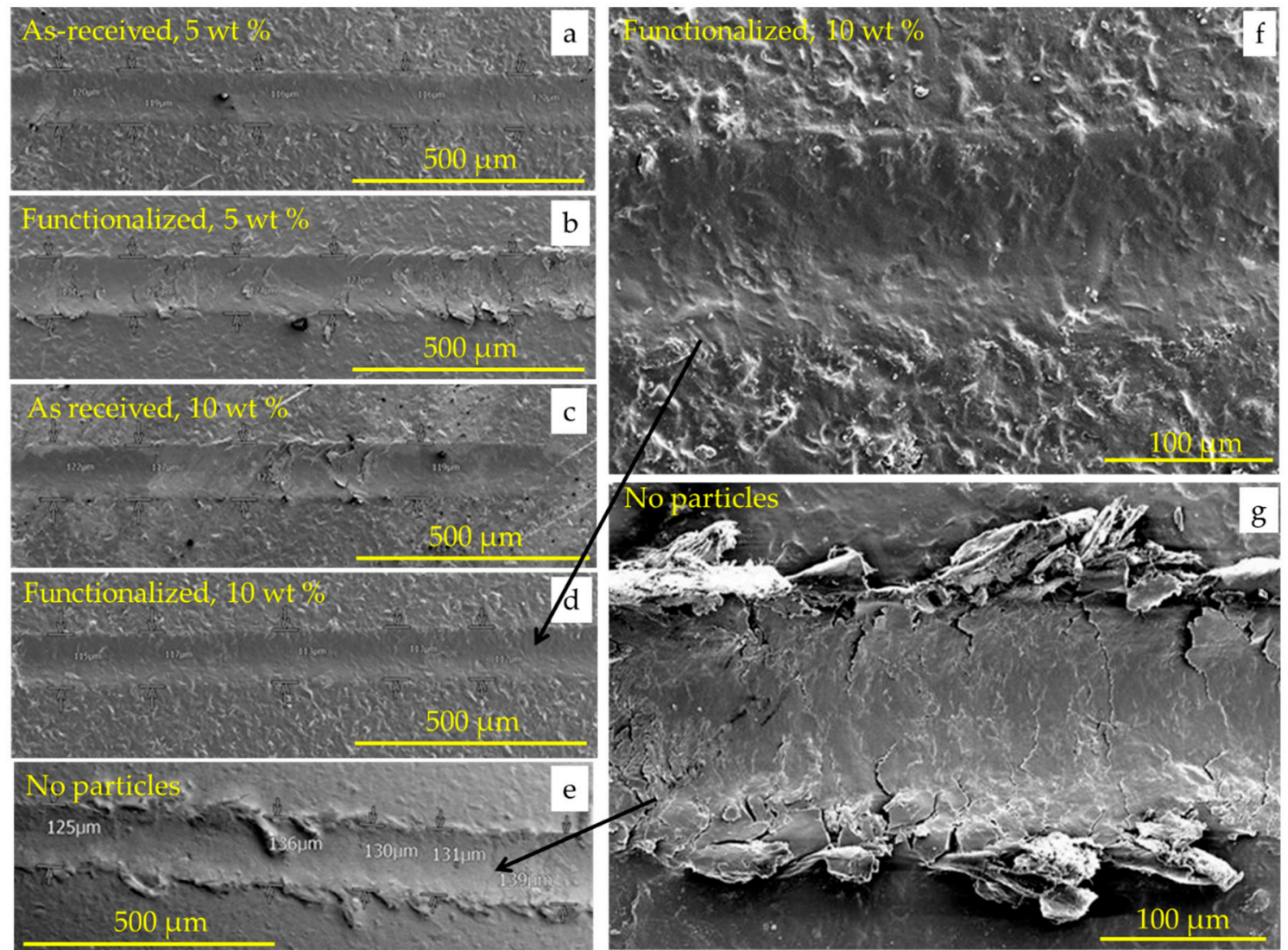

Figure 5. SEM images of laminate surfaces after the micro scratch test with a constant load of $6 \mathrm{~N}$. Laminates containing (a) $5 \mathrm{wt} \%$ of as-received particles; (b) $5 \mathrm{wt} \%$ functionalized particles; (c) $10 \mathrm{wt} \%$ of as-received particles; (d) $10 \mathrm{wt} \%$ of functionalized particles, and (e) no particles; (f,g) $10 \mathrm{wt} \%$ of functionalized particles and no particles, respectively, with higher magnification.

SEM images in Figure 5f,g show the appearance of the laminate containing $10 \mathrm{wt} \%$ functionalized particles and of the laminate with neat polymer in the middle of the scratch. It is clear that with the functionalized alumina particles, there was no additional damage to the laminate except for the scratch itself. In the case of the laminate without particles, the damage was considerable. Here, the material was pushed upwards at the edges of the scratch and in front of the indenter and micro-cracks and plastically deformed sheet-like debris were observed in the scratch zone for the sample without particles.

The results from the scratch width measurements are shown in Table 1. The results show that for the $10 \mathrm{wt} \%$ of particles added, the scratches were narrower with functionalized particles when compared to the as-received particles. This confirmed that the functionalization ensured stronger bonds and yielded narrower scratches. For $5 \mathrm{wt} \%$, the results were approximately the same with or without functionalization, stating that the amount of particles was important. 
The post-micro scratch test elastic recovery of the laminates is presented in Figure 6, Figure 6a shows the constant load of $10 \mathrm{~N}$ and Figure $6 \mathrm{~b}$ shows the progressive load from 0 to $10 \mathrm{~N}$. The recovery/healing properties were high in general and were the highest for the laminates with functionalized particles. For the laminates containing $10 \mathrm{wt} \%$ of functionalized alumina particles, the recovery was above $80 \%$ at the end of the scratch.
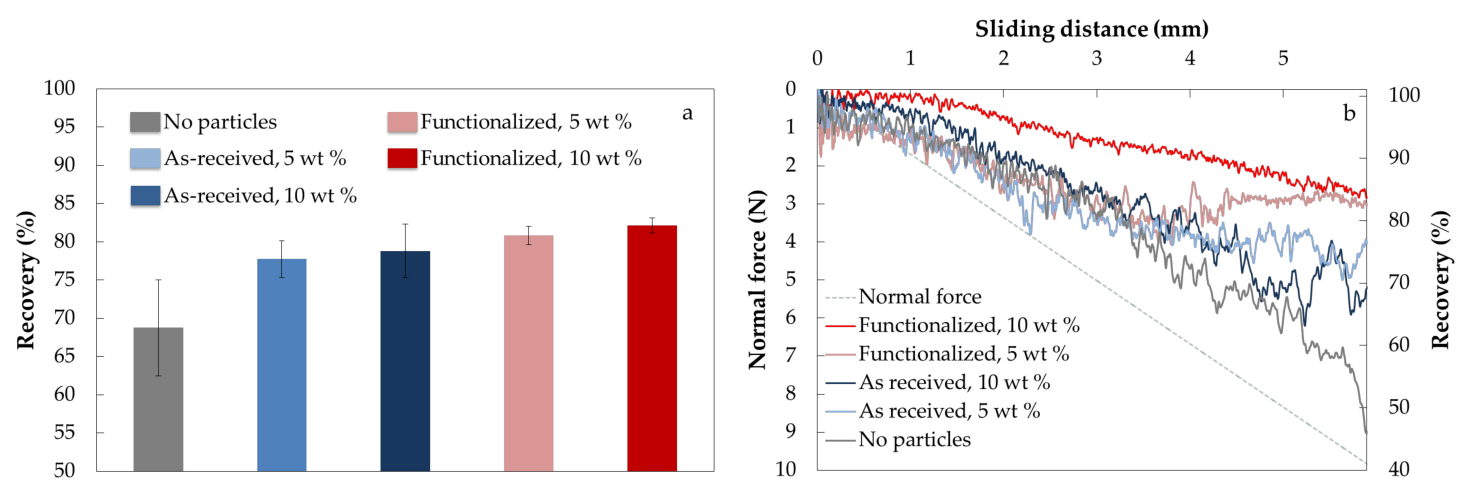

Figure 6. Elastic recovery properties of laminates after micro scratch test with (a) a constant load of $10 \mathrm{~N}$, and (b) progressive load from 0 to $10 \mathrm{~N}$ as a function of sliding distance.

In Figure 7a, the scratch hardness calculated using the post-scratch width as well as the scratch resistance obtained according to standard BS-EN 438-2 [31] are shown. There was a good correlation between the two methods for evaluating the scratch properties. Figure $7 \mathrm{~b}$ shows the critical loads for the visibility of the scratches obtained for the laminates. The laminates with functionalized alumina particles showed the highest critical loads, confirming their high ability to withstand high loads. These results confirmed good reproducibility between the different methods of evaluating the scratch resistance.
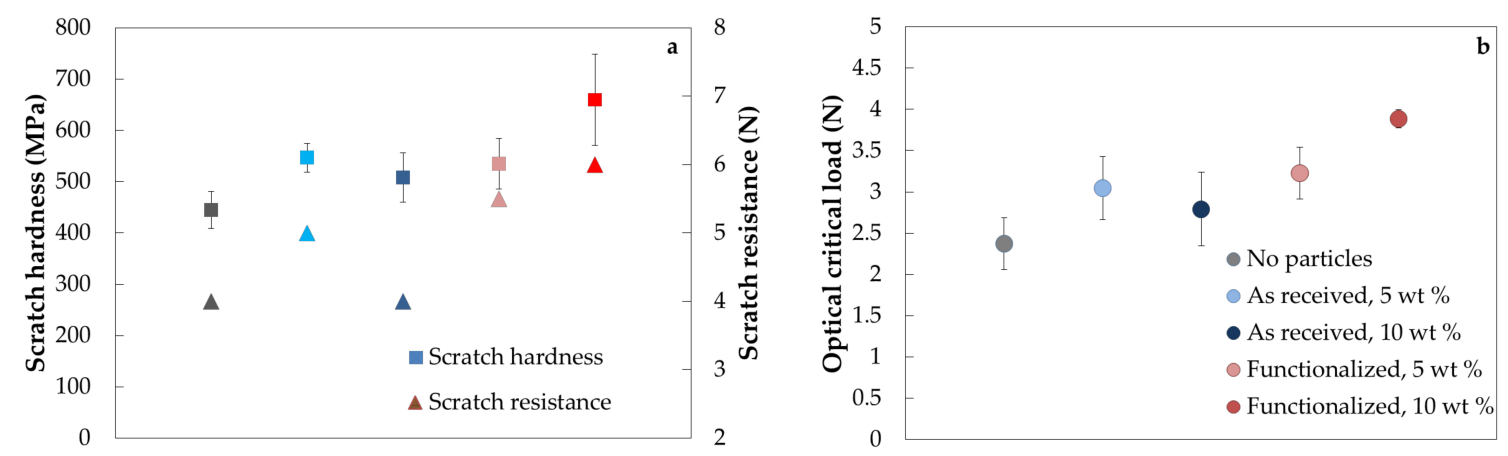

Figure 7. Scratch resistance of the laminates in terms of (a) scratch hardness and scratch resistance according to standard BS-EN 438-2, and (b) critical loads for the onset of scratch visibility in laminates containing different types of alumina particles.

\section{Discussion}

The scratch resistance of polymer composites depends mainly on the nature of the polymer, the additives, and the test conditions such as the applied load, the type of indenter, the scratching angle, and speed [32,33]. The complexity of the scratch behavior of polymers is due to their viscoplastic and viscoelastic nature [34], and the presence of additives such as reinforcing particles further complicates the material's response to scratching due to the formation of voids and cracks and the exposure of the particles during the scratching process [35]. In this work, functionalization of the reinforcing particles was shown to improve the scratch resistance of the laminates as well as the particle dispersion within the polymer matrix. Figure 3 clearly shows that the functionalization improved the distribution of 
the alumina particles within the resin. The good dispersion of the alumina particles in the laminate containing functionalized particles was due to the methoxy groups in the silane coupling agents, which contribute to the steric stabilization of the particles in the liquid phase as the polymeric chains will repulse each other. This is crucial for the performance of the laminates. It has previously been explained that while soft particles (such as agglomerates) can reduce the scratch visibility, they can also reduce the scratch hardness [12] and decrease the strength of the composite as they can act as critical flaws, especially in rigid thermosets [36] such as MF. The formation of agglomerates within the polymer matrix is therefore undesirable, and the chemical modification of the surface of the ceramic particles renders them compatible with the polymer matrix and eliminates the formation of the agglomerates.

The scratch resistance of the laminates was also significantly improved by adding functionalized particles. When comparing the results obtained from micro scratch testing, the laminate containing $10 \mathrm{wt} \%$ of functionalized particles gave the best results for the constant load measurements. The same observation could be made for the progressive load tests where the laminate containing $10 \mathrm{wt} \%$ of functionalized particles showed the best properties by far. In addition, the shapes of the residual scratch depth curves exhibited surface roughening within the scratch track for all laminates, but to a smaller extent for the one with the highest concentration of functionalized particles. This is, as was explained in a previous study [37], due to a more efficient load transfer from the matrix to the particles during the scratch test. Hence, the separation between the two phases occurred less easily and, as a result, the scratch depth decreased and the scratch resistance increased [37]. Significant differences were also seen in both the deformation extent and the deformation mechanisms when examining the scratches through microstructural investigation (Figure 5). For the neat polymer coating, the SEM images showed chipping of the surface after the scratch test all along the scratch track. However, no damage by material removal was seen on the laminate containing $10 \mathrm{wt} \%$ of functionalized particles. There seemed to be two types of deformation in the two cases: fracture-type and plastic-type, respectively [38]. By adding the functionalized particles, there was therefore a transition in the scratch feature. On one hand, the groove surface of the neat polymer was wave-like along the sliding direction and the edges of the scratch were sharp and irregular, with discontinuous margins and significant chip formation. The deformation included both grooving and cracking, with extensive brittle fracture both within the scratch path and on the edges. The surface texture of the scratch was also different from the texture of the unscratched coating. The difference in texture was less marked for the laminate containing $10 \mathrm{wt} \%$ of functionalized particles. Here, the overall features of the deformation, i.e., the smooth and continuous borders, suggest a ductile type of failure. In this case, only a small amount of material was pushed upwards at the edges of the scratch, rendering the scratch less visible. The functionalized particles were clearly reinforcing the system as less damage was seen from the scratch testing.

Higher recovery and higher scratch hardness were also obtained with particle functionalization. When recovery takes place, the bottom of the scratch moves upwards [39], and the residual depth $R_{\mathrm{d}}$ is much shallower than the penetration depth $P_{d}$. The more elastic the recovery, the smaller the scratch visibility, and these results correlated well with the visual observation results shown in Figure 7. The correlation between scratch morphology and scratch visibility is however very intricate, as it depends on may factors such as sample color, illumination, angle and duration of inspection, psychological perception as well as the size and type of damage [38]. Here, the large recovery in the scratch depth seems to be favored by the presence of the functionalized particles and it is likely that this decreased the brittleness of the polymer. The parameters influencing the recovery appear to be complex and the addition of particles can contribute to the recovery by increasing the free volume in the composite $[40,41]$. The phenomenon has been observed, for example, when adding silica particles, both micro- and nano-sized, to acrylic-based polyurethane coatings [41]. In this work, both non-functionalized and functionalized particles contributed to the increase in elastic properties and therefore the scratch resistance, but the functionalized particles did so to a larger extent. The same 
conclusion could be reached when examining the values for the critical loads, which were also higher for the laminate with a high content of functionalized alumina particles.

The enhanced scratch resistance could also be associated with a decrease in the mobility of the polymer molecules near the interface, under the influence of the fillers. The scratch resistance of the polymers and polymer composites has indeed been reported to increase with an increase in the glass transition temperature [42,43]. The enhanced glass transition temperature of polymeric composites is due to a decrease in the mobility of the polymer molecules near the interface and depends on the degree of interaction between the filler material and the polymer as well as on the interfacial area [44]. The increase in scratch resistance when adding the functionalized alumina particles to the polymer matrix can thus be attributed to an increase in the glass transition temperature and to the reduced mobility of the polymer molecules and also to the stronger interactions within the resin.

For decorative laminates, the scratch visibility is crucial and is related to the damage mechanisms and to the scratch dimensions and morphology. Brittle fractures will increase the roughness of the scratch path, chipping, shoulder formation, and scratch width. All these factors significantly affect the scratch visibility. Adding functionalized alumina particles to the polymer will decrease the scratch visibility by influencing the scratch deformation mode and, despite the subjectivity of the visual observation method used in the laminate industry to assess scratch resistance, the results correlated well with the results obtained with micro scratch testing and with the ones obtained through SEM observation.

\section{Conclusions}

The addition of alumina particles increased the scratch resistance of the laminates. Functionalization increased the scratch resistance further, with the best results obtained with a $10 \mathrm{wt} \%$ of functionalized alumina particles. An improved distribution of the particles within the resin was obtained, and the scratch resistance improvement achieved for the laminates was clearly dependent on the content and dispersion state of the particles.

Depth of the scratches and morphologies of the scratch tracks provided an insight into the deformation mode. The shape of the scratch tracks gave an indication as to the severity of the deformation as well as the scratching mechanism. By adding functionalized alumina particles, the scratch surface damage changed from extensive cracking and tearing to ductile plowing with no cracks inside the scratch track. The high scratch recovery had a great influence on the scratch visibility. Scratch recovery of the neat polymer in this study was relatively high and the addition of the functionalized alumina led to an increase in the scratch resistance and scratch hardness, but also to a reduction in scratch visibility since it further improved the recovery characteristics of the coating.

Author Contributions: Conceptualization, C.L.R., H.L.L., M.-A.E., M.B., and G.C.-C.; Methodology, C.L.R., H.L.L., M.-A.E., M.B., and G.C.-C.; Validation, C.L.R., H.L.L., M.-A.E., M.B., and G.C.-C.; Formal Analysis, C.L.R.; Investigation, C.L.R.; Resources, C.L.R., H.L.L., M.-A.E., M.B., and G.C.-C.; Data Curation, C.L.R. and T.I.H.; Writing-Original Draft Preparation, C.L.R.; Writing-Review \& Editing, H.L.L., M.-A.E., M.B., and G.C.-C.; Visualization, C.L.R.; Supervision, H.L.L., M.-A.E., M.B., and G.C.-C.; Project Administration, L.K.H. and H.L.L.; Funding Acquisition, L.K.H.

Funding: This research was funded by the Research Council of Norway; the Elephant Floor project, Grant no. 228644.

Acknowledgments: We deeply acknowledge Per Olav Johnsen for his help and expertise on the SEM experiments.

Conflicts of Interest: The authors declare no conflict of interest.

\section{References}

1. Lepedat, K.; Wagner, R.; Lang, J. Laminates. In Phenolic Resins: A Century of Progress; Springer: Berlin/Heidelberg, Germany, 2010; pp. 243-261.

2. Krupička, A.; Johansson, M.; Hult, A. Use and interpretation of scratch tests on ductile polymer coatings. Prog. Org. Coat. 2003, 46, 32-48. [CrossRef] 
3. Hara, Y.; Mori, T.; Fujitani, T. Relationship between viscoelasticity and scratch morphology of coating films. Prog. Org. Coat. 2000, 40, 39-47. [CrossRef]

4. Sobhani, H.; Khorasani, M.M. Optimization of scratch resistance and mechanical properties in wollastonite-reinforced polypropylene copolymers. Polym. Adv. Technol. 2016, 27, 765-773. [CrossRef]

5. Nemli, G. Factors affecting some quality properties of the decorative surface overlays. J. Mater. Process. Technol. 2008, 195, 218-223. [CrossRef]

6. Hossain, M.M.; Jiang, H.; Sue, H.-J. Effect of constitutive behavior on scratch visibility resistance of polymers-A finite element method parametric study. Wear 2011, 270, 751-759. [CrossRef]

7. Browning, R.L.; Jiang, H.; Sue, H.-J. Scratch behavior of polymeric materials. In Tribology of Polymeric Nanocomposites: Friction and Wear of Bulk Materials and Coatings, 2nd ed.; Friedrich, K., Schlarb, A.K., Eds.; Butterworth-Heinemann: Oxford, UK, 2013; pp. 513-550.

8. Brostow, W.; Cassidy, P.E.; Macossay, J.; Pietkiewicz, D.; Venumbaka, S. Connection of surface tension with multiple tribological properties in epoxy + fluoropolymer systems. Polym. Int. 2003, 52, 1498-1505. [CrossRef]

9. Xiang, C.; Sue, H.J.; Chu, J.; Coleman, B. Scratch behavior and material property relationship in polymers. J. Polym. Sci. 2000, 39, 47-59. [CrossRef]

10. Jin, P.W.; Benca, K.R.; Quarmby, I.C.; Kurpiewski, T.; Ferrell, V.E. Enhanced Scratch Resistant Coatings Using Inorganic Fillers. U.S. Patent 6,844,374, 18 January 2005.

11. Barna, E.; Bommer, B.; Kürsteiner, J.; Vital, A.; Trzebiatowski, O.V.; Koch, W.; Schmid, B.; Graule, T. Innovative, scratch proof nanocomposites for clear coatings. Compos. Part A 2005, 36, 473-480. [CrossRef]

12. Kurkcu, P.; Andena, L.; Pavan, A. An experimental investigation of the scratch behaviour of polymers-2: Influence of hard or soft fillers. Wear 2014, 317, 277-290. [CrossRef]

13. Antunes, P.V.; Ramalho, A.; Carrilho, E.V.P. Mechanical and wear behaviours of nano and microfilled polymeric composite: Effect of filler fraction and size. Mater. Des. 2014, 61, 50-60. [CrossRef]

14. Chauhan, S.R.; Thakur, S. Effects of particle size, particle loading and sliding distance on the friction and wear properties of cenosphere particulate filled vinylester composites. Mater. Des. 2013, 51, 398-408. [CrossRef]

15. Niezgoda, S.; Gupta, V.; Knight, R.; Cairncross, R.A.; Twardowski, T.E. Effect of reinforcement size on the scratch resistance and crystallinity of HVOF sprayed nylon-11/ceramic composite coatings. J. Therm. Spray Technol. 2006, 15, 731-738. [CrossRef]

16. Farzaneh, S.; Tcharkhtchi, A. Viscoelastic properties of polypropylene reinforced with mica in $T_{\alpha}$ and $T_{\alpha c}$ transition zones. Int. J. Polym. Sci. 2011, 2011, 427095. [CrossRef]

17. Sangermano, M.; Messori, M. Scratch resistance enhancement of polymer coatings. Macromol. Mater. Eng. 2010, 295, 603-612. [CrossRef]

18. Cayton, R.H.; Brotzman, R.W. Nanocomposite coatings-Applications and properties. Mater. Res. Soc. Symp. Proc. 2011, 703, V8.1. [CrossRef]

19. Wang, Y.; Lim, S.; Luo, J.L.; Xu, Z.H. Tribological and corrosion behaviors of $\mathrm{Al}_{2} \mathrm{O}_{3}$ / polymer nanocomposite coatings. Wear 2006, 260, 976-983. [CrossRef]

20. Bauer, F.; Gläsel, H.-J.; Decker, U.; Ernst, H.; Freyer, A.; Hartmann, E.; Sauerland, V.; Mehnert, R. Trialkoxysilane grafting onto nanoparticles for the preparation of clear coat polyacrylate systems with excellent scratch performance. Prog. Org. Coat. 2003, 47, 147-153. [CrossRef]

21. Ye, S.; Azarnoush, S.; Smith, I.R.; Cramer, N.B.; Stansbury, J.W.; Bowman, C.N. Using hyperbranched oligomer functionalized glass fillers to reduce shrinkage stress. Dent. Mater. 2012, 28, 1004-1011. [CrossRef] [PubMed]

22. Mallakpour, S.; Madani, M. A review of current coupling agents for modification of metal oxide nanoparticles. Prog. Org. Coat. 2015, 86, 194-207. [CrossRef]

23. Ambrósio, J.D.; Balarim, C.V.M.; de Carvalho, G.B. Preparation, characterization, and mechanical/tribological properties of polyamide 11/Titanium dioxide nanocomposites. Polym. Compos. 2016, 37, 1415-1424. [CrossRef]

24. Barna, E.; Rentsch, D.; Bommer, B.; Vital, A.; Trzebiatowski, O.V.; Graule, T. Surface modification of nanoparticles for scratch resistant clear coatings. Kautsch. Gummi Kunstst. 2007, 60, 49-51.

25. Solvent Stabilizer Systems. 2017. Available online: https://www.sigmaaldrich.com/chemistry/solvents / learning-center/stabilizer-systems.html (accessed on 14 December 2017). 
26. Ap-silane 51, 2015. Available online: https:/ / static1.squarespace.com/static/57a6c9e1440243dad487f1d6/t/ 57b32c5746c3c465f616adbc/1471360088338/AP-SILANE+51+-+TDS.pdf (accessed on 30 March 2018).

27. Guo, Z.; Pereira, T.; Choi, O.; Wang, Y.; Hahn, H.T. Surface functionalized alumina nanoparticle filled polymeric nanocomposites with enhanced mechanical properties. J. Mater. Chem. 2006, 16, 2800-2808. [CrossRef]

28. ASTM D7027-13 Standard Test Method for Evaluation of Scratch Resistance of Polymeric Coatings and Plastics Using an Instrumented Scratch Machine; ASTM International: West Conshohocken, PA, USA, 2013.

29. Bucaille, J.L.; Felder, E.; Hochstetter, G. Mechanical analysis of the scratch test on elastic and perfectly plastic materials with the three-dimensional finite element modeling. Wear 2001, 249, 422-432. [CrossRef]

30. Rangarajan, P.; Sinha, M.; Watkins, V.; Harding, K.; Sparks, J. Scratch visibility of polymers measured using optical imaging. Polym. Eng. Sci. 2003, 43, 749-758. [CrossRef]

31. BS EN 438-2:2016 High-Pressure Decorative Laminates (HPL). Sheets Based on Thermosetting Resins (Usually Called Laminates). Part 2: Determination of Properties; British Standards Institution: London, UK, 2016.

32. Rajesh, J.J.; Bijwe, J. Investigations on scratch behaviour of various polyamides. Wear 2005, 259, 661-668. [CrossRef]

33. Briscoe, B.J.; Sinha, S.K. Scratch resistance and localised damage characteristics of polymer surfaces-A review. Materialwiss. Werkstofftech. 2003, 34, 989-1002. [CrossRef]

34. Al-Rub, R.K.A.; Tehrani, A.H.; Darabi, M.K. Application of a large deformation nonlinear-viscoelastic viscoplastic viscodamage constitutive model to polymers and their composites. Int. J. Damage Mech. 2015, 24, 198-244. [CrossRef]

35. Wong, M.; Moyse, A.; Lee, F.; Sue, H.-J. Study of surface damage of polypropylene under progressive loading. J. Mater. Sci. 2004, 39, 3293-3308. [CrossRef]

36. Rothon, R.N. Particulate Fillers for Polymers; Rapra review reports, Vol. 12; Smithers Rapra Publishing: Shrewsbury, UK, 2002.

37. Khalilnezhad, P.; Sajjadi, S.A.; Zebarjad, S.M. Effect of nanodiamond surface functionalization using oleylamine on the scratch behavior of polyacrylic/nanodiamond nanocomposite. Diam. Relat. Mater. 2014, 45, 7-11. [CrossRef]

38. Lin, L.; Blackman, G.S.; Matheson, R.R. A new approach to characterize scratch and mar resistance of automotive coatings. Prog. Org. Coat. 2000, 40, 85-91. [CrossRef]

39. Brostow, W.; Deborde, J.-L.; Jaklewicz, M.; Olszynski, P. Tribology with emphasis on polymers: Friction, scratch resistance and wear. J. Mater. Educ. 2003, 24, 119-132.

40. Brostow, W.; Hagg Lobland, H.E.; Narkis, M. Sliding wear, viscoelasticity, and brittleness of polymers. J. Mater. Res. 2006, 21, 2422-2428. [CrossRef]

41. Zhou, S.; Wu, L.; Sun, J.; Shen, W. The change of the properties of acrylic-based polyurethane via addition of nano-silica. Prog. Org. Coat. 2002, 45, 33-42. [CrossRef]

42. Lange, J.; Luisier, A.; Hult, A. Influence of crosslink density, glass transition temperature and addition of pigment and wax on the scratch resistance of an epoxy coating. J. Coat. Technol. 1997, 69, 77-82. [CrossRef]

43. Rink, H.-P. Polymeric engineering for automotive coating applications. In Automotive Paints and Coatings; Streitberger, H.-J., Kreis, W., Eds.; Wiley-VCH Verlag GmbH \& Co. KGaA: Chichester, UK, 2008; pp. 211-257.

44. Droste, D.H.; Dibenedetto, A.T. The glass transition temperature of filled polymers and its effect on their physical properties. J. Appl. Polym. Sci. 1969, 13, 2149-2168. [CrossRef]

(C) 2018 by the authors. Licensee MDPI, Basel, Switzerland. This article is an open access article distributed under the terms and conditions of the Creative Commons Attribution (CC BY) license (http://creativecommons.org/licenses/by/4.0/). 